\title{
Prevalence of Staphylococcus Species from Clinical Samples Obtained from Some Hospitals on Kano Metropolis, Nigeria
}

\author{
Sadiya M Ibrahim ${ }^{1}$, Farouk S Nas ${ }^{2}$, Kabiru A Garba ${ }^{3}$ and Muhammad Ali*4 \\ ${ }^{1}$ Department of Integrated Science, Sa'adatu Rimi College of Education Kumbotso, Kano, Nigeria \\ ${ }^{2}$ Department of Biological Sciences, Bayero University Kano, Nigeria \\ ${ }^{3}$ School of Nursing Madobi, Kano, Nigeria \\ ${ }^{4}$ Department of Microbiology, Federal University Gusau, Nigeria
}

*Corresponding author: Muhammad Ali, Department of Microbiology, Federal University, Nigeria.

To Cite This Article: Muhammad Ali. Prevalence of Staphylococcus Species from Clinical Samples Obtained from Some Hospitals on Kano Metropolis, Nigeria. Am J Biomed Sci \& Res. 2019 - 5(3). AJBSR.MS.ID.000913. DOI: 10.34297/AJBSR.2019.05.000913.

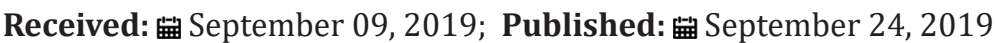

\begin{abstract}
The study was aimed to determine prevalence of Staphylococcus species among patients attending some hospitals in Kano, Northern Nigeria. Three hundred (300) samples from ear swab, high vaginal swab (HVS), wound swab and urine were collected from patients (133 males and 167 females) attending the Hospitals over a period of eight months (October, 2016 to May, 2017). The samples collected inoculated onto the surface of freshly prepared Nutrient agar for colony formation and isolation. Each colony was isolated in a pure form by sub culturing for further studies and identification. The result showed that the distribution of Staphylococcus aureus and other Coagulase Negative Staphylococcus in the clinical samples for the three hospitals, S. aureus was isolated most from wound swab with 51 isolates (33.33\%) followed by ear swab with 46 isolates (30.07\%) and then H.V.S and urine with 28 isolates accounted for (18.30\%) each. CoNS was isolated most from urine sample with 11 isolates (36.67\%) followed by H.V.S with 9 isolates (30.00\%) then ear swab with 8 isolates (29.51) and wound swab, 2 isolates accounted for (6.67\%). Statistical analysis of the result showed significant difference in the prevalence of Staphylococcus species among the samples examined at $p<0.05$. Staphylococci are one of the etiologic agents of infectious diseases.
\end{abstract}

Keywords: Clinical samples; infections; Kano; prevalence; Staphylococcus species

\section{Introduction}

Staphylococci are frequently isolated as etiologic agents of infectious processes, with Staphylococcus aureus being the most important human pathogen. S. aureus causes superficial and deep skin and soft tissue infections, bacteremia with metastatic Staphylococci are frequently isolated as etiologic agents of infectious processes, with Staphylococcus aureus being the abscess formation, and a variety of toxin-mediated diseases, including gastroenteritis, staphylococcal scalded skin syndrome, and toxic shock syndrome [1]. S. aureus has long been recognized as one of the most important bacteria that cause disease in humans. It is the leading cause of skin and soft tissue infections such as abscesses (boils), furuncles and cellulitis. Although most Staphylococcal infections are not serious, S. aureus can cause serious infections such as blood stream infections, pneumonia, or bone and joint infections [2]. S. aureus can also cause serious infections such as pneumonia (infection of the lungs) or bacteremia (bloodstream infection), symptoms of these infections include: difficulty breathing, malaise, fever or chills [2].
In addition, two coagulase-negative staphylococcal species, S. epidermidis and S. saprophyticus, are also recognized as important agents of human infections. S. epidermidis is associated with infections of indwelling devices, osteomyelitis, wound infections, peritoneal dialysis catheter-associated peritonitis, and nosocomial bacteremia [3]. S. saprophyticus is recognized primarily as a cause of acute urinary tract infections in young women [4]. Together, these two coagulase-negative species comprise the greater majority of the clinically significant coagulase-negative staphylococci recovered from human specimens [5]. Staphylococcus epidermidis is isolated prevalently from human epithelia and colonizes predominantly the axillae, head, and nares [6]. S. epidermidis belongs to the group of coagulase-negative staphylococci (CoNS), which is discriminated from coagulase- positive Staphylococci, such as S. aureus by its lack of the enzyme coagulase [7]. Indeed, this pathogen is part of the human epithelia microflora and for this reason has a benign relationship with the host, but S. epidermidis has emerged as a pathogen causing different infections. Particularly, S. epidermidis 
represents the most frequent causative agent involved with infections involving any kind of medical devices, such as peripheral or central intravenous catheters [8]. Specifically, catheter-related infections are associated with increased mortality and contribute to an increased length of hospital stay and higher healthcare costs, which are problematic in limited-resource settings [9].

Staphylococcus saprophyticus is uniquely associated with un- complicated urinary tract infection (UTI) in humans. It has special urotropic and ecologic features that are distinctly different from other staphylococci and from Escherichia coli. This article will consider the epidemiology, ecology, pathogenesis, and clinical features of infections caused by this microorganism. Much more needs to be learned about the epidemiology and natural history of UTI caused by S. saprophyticus as well as the role of S. saprophyticus in human and animal health and disease. A series of research questions are offered to address these issues. Coagulase-negative staphylococci were considered to be urinary contaminants prior to the 1960s. In 1962, Torres Pereira [10] reported the isolation of coagulase-negative staphylococci possessing antigen 51 from the urine of women with acute UTI. In subsequent years, additional reports supported this concept [11]. The laboratory identification of S. aureus has traditionally depended on the demonstration of coagulase production by the tube coagulase test [12]. Susceptibility to novobiocin is a factor widely used in clinical laboratories for the presumptive identification of S. saprophyticus [13]. The study was aimed to determine prevalence of Staphylococcus species among patients attending some hospitals in Kano, Northern Nigeria.

\section{Materials and Methods}

\section{Study Area}

The research was conducted in Kano central area which lies between Latitude 11.90 North and Longitude 8.50 East in North western Nigeria, Kano state occupies 20,131 square kilometers and is bounded to the North west by Katsina State, North east by Jigawa State to the north east and south by Bauchi and Kaduna. The area is densely populated comprising of 9,383,682 [14].

\section{Ethical Clearance}

Ethical approval was obtained from Kano State Hospital Management Board based on the consent of Murtala Muhammad Specialist Hospital, Muhammad Abdullahi Wase Specialist Hospital and Aminu Kano Teaching Hospital ethical committees.

\section{Sample Size}

Atotal of 300 samples were collected, a standard epidemiological formula (Fisher's formula) was used to calculate the sample size. The prevalence and antimicrobial susceptibility of MRSA and CoNS isolated from healthy students in Ota, Nigeria as reported by Joshua and Ronke [15] was $78 \%$ this was scaled to 300 at $95 \%$ confidence interval, and the sample size was calculated using a formula by Fishers.
$\mathrm{N}=\mathrm{Z} 2 \mathrm{pq} / \mathrm{d} 2$

Where:

$\mathrm{N}=$ sample size

$\mathrm{Z}=$ Standard normal deviate at 95\% confidence interval.

$\mathrm{P}=$ Proportion of target population

$q=1-p$

$\mathrm{d}=$ degree of freedom.

$\mathrm{Z}=1.962, \mathrm{p}=0.78, \mathrm{q}=1-0.0 .78=0.22 \mathrm{~d}=0.052$

Thus;

$\mathrm{N}=0.65921856 / 0.0025=263.7$

Therefore, a total of 263.7 with 14\% (36.8) of this subject will be added to the research for attrition, making a total of approximately 300 samples was involved in the study.

\section{Sample Collection}

Three hundred (300) samples from ear swab $(n=75)$, high vaginal swab (HVS) $(n=75)$, wound swab $(n=75)$ and urine $(n=75)$ were collected from patients (133 males and 167 females) attending three different hospitals within Kano State metropolis (Murtala Muhammad Specialist Hospital, Muhammad Abdullahi Wase Specialist Hospital and Aminu Kano Teaching Hospital) using sterile swab sticks and bottles over a period of eight months (October, 2016 to May, 2017) (Table 1).

\begin{tabular}{|c|c|c|}
\hline \multicolumn{3}{|l|}{ Table 1: Sample sources and number. } \\
\hline S/N & Sample source & Number \\
\hline 1 & Ear swab & 75 \\
\hline 2 & High vaginal swab & 75 \\
\hline 3 & Wound swab & 75 \\
\hline 4 & Urine & 75 \\
\hline & Total & 300 \\
\hline
\end{tabular}

\section{Isolation and Identification of Staphylococcal species}

The ear swab, high vaginal swab (HVS), wound swab and urine samples collected inoculated onto the surface of freshly prepared Nutrient agar (Biomark). The plates were incubated at $37^{\circ} \mathrm{C}$ for $24 \mathrm{~h}$ for colony formation. Each colony was isolated in a pure form by sub culturing for further studies and identification. Discrete colonies of each isolate were kept in peptone water. The bacterial strains were then stored at $40 \mathrm{C}$ for further experiments [16]. The isolated organisms were subjected to Gram staining, Mannitol fermentation and Biochemical tests (Catalase, coagulase, DNase, haemolysis test) as described by Zaved et al. [17] and Cheesbrough [18] for identification.

\section{Statistical Analysis}

The data generated were subjected to descriptive statistical analysis using percentages and Chi - square analysis was used in 
determining the prevalence rates. $\mathrm{p}<0.05$ was considered indicative of a statistically significant difference.

\section{Results}

\section{Age Distribution of the Patients}

The Table 2 described the age distribution of the patients where the higher occurrence of the infection with Staphylococcus was observed in the age group 0-15 in all the three hospitals were the research was conducted namely Murtala Muhammad Specialist Hospital, Muhammad Abdullahi Wase Specialist Hospital and Aminu Kano Teaching Hospital with 28(27.18\%), 27(25.71\%) and $26(28.26 \%)$ respectively, followed by the age group 16-25 with $21(20.39 \%), 24(22.86 \%)$ and $24(26.09 \%)$ while the infection was lower in the age group $>55$ years old patients with $4(3.88 \%)$, $6(5.71 \%)$ and $3(3.26 \%)$. However, the result is not significant at $\mathrm{p}<0.05$ (Table 2).

\begin{tabular}{|c|c|c|c|c|c|}
\hline Age & MMSH (\%) & MAWSH (\%) & AKTH (\%) & Total (\%) & $\mathrm{X} 2$ \\
\hline $0-15$ & $28(27.18)$ & 27 (25.72) & $26(28.26)$ & $81(27.00)$ & $1.1318^{*}$ \\
\hline $16-30$ & $26(25.26)$ & 27 (25.72) & $23(25.00)$ & 79 (26.34) & \\
\hline $31-45$ & $24(23.30)$ & $25(23.80)$ & 21 (22.83) & 67 (22.33) & \\
\hline $46-60$ & $21(20.38)$ & $20(19.05)$ & $19(20.65)$ & $60(20.00)$ & \\
\hline 61 - above & $04(03.88)$ & $06(05.71)$ & $03(03.26)$ & $13(04.33)$ & \\
\hline Total & $103(100)$ & $105(100)$ & $92(100)$ & $300(100)$ & \\
\hline
\end{tabular}

Key: *The table value is 0.99727 , and the result is not significant at $p<0.05$. MMSH: Murtala Muhammad Specialist Hospital; MAWSH: Muhammad Abdullahi Wase Specialist Hospital; AKTH: Aminu Kano Teaching Hospital.

\section{Sex distribution of the patients}

Table 3 described the sex distribution of the patients and higher occurrence of the infection was observed in female patients than male in all the three hospitals were the research was

conducted with 46 (44.66\%), 49 (46.67\%) and 38 (41.30\%) for male and 57 (55.34\%), 56 (53.33\%) and 54 (58.69\%) for female in MMSH, MAWSH and AKTH respectively. However, the result is not significant at $\mathrm{p}<0.05$ (Table 3).

\begin{tabular}{|c|c|c|c|c|c|}
\hline \multicolumn{7}{|l|}{ Table 3: Sex Distributions of the Patients with Percentage Prevalence. } \\
\hline Sex & MMSH (\%) & MAWSH (\%) & AKTH (\%) & Total (\%) & X2 \\
\hline Male & $46(44.66)$ & $49(46.67)$ & $38(41.30)$ & $133(44.33)$ & $0.5781 *$ \\
\hline Female & $57(55.34)$ & $56(53.33)$ & $54(58.69)$ & $167(55.66)$ & $300(100)$ \\
\hline Total & $103(100)$ & $105(100)$ & $92(100)$ & 300 \\
\hline
\end{tabular}

Key: ${ }^{*}$ The table value is .74896 , and the result is not significant at $p<0.05$. MMSH: Murtala Muhammad Specialist Hospital; MAWSH: Muhammad Abdullahi Wase Specialist Hospital; AKTH: Aminu Kano Teaching Hospital.

\section{Prevalence of Staphylococcus species}

Table 4 described the distribution of Staphylococcus aureus and other Coagulase Negative Staphylococcus in the clinical samples for the three hospitals, S. aureus was isolated most from wound swab with 51 isolates (33.33\%) followed by ear swab with 46 isolates
(30.07\%) and then H.V.S and urine with 28 isolates accounted for $(18.30 \%)$ each. CoNS was isolated most from urine sample with 11 isolates (36.67\%) followed by H.V.S with 9 isolates (30.00\%) then ear swab with 8 isolates (29.51) and wound swab, 2 isolates accounted for $(6.67 \%)$ (Table 4$)$.

\begin{tabular}{|c|c|c|c|c|}
\hline Table 4: Prevalence of Staphylococcus aureus and other Non- Staphylococcus aureus in the Clinical Samples from the Three Hospitals. \\
\hline Sample source & S. aureus (\%) & Non- S. aureus (\%) & Total (\%) & X2 \\
\hline Ear swab & $46(30.07)$ & $08(26.66)$ & $54(29.51)$ & $11.9245^{*}$ \\
\hline Wound swab & $51(33.33)$ & $02(06.67)$ & $53(28.96)$ & $37(20.22)$ \\
\hline HVS & $28(18.30)$ & $09(30.00)$ & $39(21.31)$ & \\
\hline Urine & $28(18.30)$ & $11(36.67)$ & $183(100)$ & \\
\hline Total & $153(100)$ & $30(100)$ & & \\
\hline
\end{tabular}

Key: *The table value is .007646 , and the result is significant at $p<0.05$.

\section{Discussion}

Staphylococcus is innocuous in most environment but with remarkable adaptability and versatility which has equipped it as a commensal and pathogen. S. aureus is one of the most infectious agents with high prevalence in various communities and healthcare institutions [19]. The study aimed to determination the prevalence of some Staphylococcus species from clinical samples obtained from some Hospitals in Kano Metropolis. A total of 183 Staphylococcus species from ear swab, H.V.S, urine and wound swab samples was isolated out of 300 samples collected from three Hospitals for the research (i.e. Murtala Muhammad Specialist Hospital, Muhammad Abdullahi Wase Specialist Hospital and Aminu Kano Teaching Hospital). 
Both children and adults were included and higher incidence was observed between the ages of 0-15 years with $28(27.18 \%)$ in MMSH and lower incidence was observed between the ages above 55 years with $3(3.26 \%)$ in AKTH as shown in Table 2. Female were most infected than male in all the three hospitals with $57(55.34 \%), 56(53.33 \%)$ and 54(58.69\%) in MMSH, MAWSH and AKTH respectively. The incidence of S. aureus and other CoNS for the three hospitals treated was $153(83.61 \%)$ S. aureus and 30 (16.39\%) CoNS, this shows the versatility of S. aureus amongst other Staphylococci which makes it most endemic pathogen in clinical settings. The highest incidence of S. aureus was seen in wound swab 51 (33.33\%) followed by ear swab 46 (30.07\%), then urine and H.V.S with 28 (18.30\%) both, while CoNS was isolated most in urine sample with 11 (36.67\%), followed by HVS with 9 $(30 \%)$ then ear swab with $8(26.67 \%)$ and lastly wound swab with $2(6.67 \%)$.

The highest incidence of CoNS in urine was consistent with the similar reports of Nwoire et al. [19] titled "Incidence of S. aureus in clinical specimens in federal teaching Hospital, Abakaliki, Ebonyi State" which has $60.4 \%$ and that of Joshua and Ronke [15] titled "prevalence and antimicrobial susceptibility of methicillin resistant Staphylococcus aureus and coagulase-negative Staphylococci isolated from apparently health university students in Ota, Nigeria" with $43.6 \%$. The higher incidence in wound swab sample could be attributed to poor personal hygiene and exposure of the wounds, which might have made it more prone to contamination and infection. Furthermore, most people in this area tend to treat their wounds on their own or employ services of ill-trained quacks before seeking medical attention which could account for the level of colonization by S. aureus and other Staphylococcus species in wounds.

The non-coagulase Staphylococci identified amongst these samples might have been contaminants or opportunistic pathogens; which is in consistent with the report titled isolation of coagulasenegative Staphylococci and catalase negative organism in the urine of high school children in Abakaliki. It is well known that other Staphylococci though normal commensals are opportunistic pathogen of man [20].

\section{Conclusion}

The study has demonstrated the occurrence of S. aureus and other CoNS in the clinical samples analyzed in the research. The distribution of Staphylococcus aureus and other Coagulase Negative Staphylococcus in the clinical samples for the three hospitals showed that $\mathrm{S}$. aureus was isolated most from wound swab followed by ear swab and then H.V.S and urine with 28 isolates each. CoNS was isolated most from urine sample followed by H.V.S then ear swab and wound swab. It is recommended that individual should practice good hygiene exercise to avoid the spread of infection with Staphylococci.

\section{Acknowledgement}

The authors wish to acknowledge to the Kano State Government through Health Service Management Board for the ethical approval and sample provision from the Hospitals. Thanks to technical staff of Biological Science Department of Kano University of Science and Technology Wudil for use of Laboratory facilities.

\section{References}

1. Ryan KJ, Ray CG (2004) Sherris Medical Microbiology ( $4^{\text {th }}$ edn), Mc Graw Hill, USA.

2. Minnesota Department of Health Fact Sheet (2010) Infectious Disease Epidemiology, Prevention and Control.

3. Brooks GF, Janets SB, Stephen AM (2001) Medical Microbiology $\left(22^{\text {nd }}\right.$ edn), Mc Grow-Hill, USA.

4. Archer GL (1990) Staphylococcus epidennidis and other coagu- lase-negative staphylococci. In: GL Mandel, et al. (Eds.), Principles and practice of infectious diseases, ( $3^{\text {rd }}$ edn), Churchill-Livingstone, New York, USA, pp. 1511-1518.

5. Waldvogel FA (1990) Staphylococcus aureus (including toxic shock syndrome). In GL Mandell, et al. (Eds.), Principles and practice of infectious diseases, ( $3^{\text {rd }}$ edn), Churchill Livingstone, New York, USA, pp. 1489-1510.

6. Kloos WE, Musselwhite MS (1975) Distribution and persistence of Staphylococcus and Micrococcus species and other aerobic bacteria on human skin. Appl Microbiol 30: 381-385.

7. Otto M (2009) Staphylococcus epidermidis--the "accidental" pathogen. Nat Rev Microbiol 1 7(8): 555-567.

8. Rogers KL, Fey PD, Rupp ME (2009) Coagulase-negative staphylococcal infections. Infect Dis Clin North Am 23(1): 73- 98.

9. Rosenthal VD, Bijie H, Maki DG, Mehta Y, Apisarnthanarak A, Medeiros EA, et al. (2012) International Nosocomial Infection Control Consortium (INICC) report, data summary of 36 countries, for 2004-2009. Am J Infect Control 40(5): 396-407.

10. Torres Pereira A (1992) Coagulase-negative strains of staphylococcus possessing antigen 51 as agents of urinary infection. J Clin Pathol 15: 252-253.

11. Maskell R (2004) Importance of coagulase-negative staphylococci as pathogens in the urinary tract. Lancet 1(7867): 1155-1158.

12. Kloos WE, DW Lambe Jr (1991) Staphylococcus. In: A Balows, et al. (Eds.), Manual of clinical microbiology, ( $5^{\text {th }}$ edn), American Society for Microbiology, Washington DC, USA, pp. 222-237.

13. Goldstein J, R Schulman, E Kelley, G McKinley G, Fung J (1983) Effect of different media on determination of novobiocin resistance for differentiation of coagulase-negative staphylococci. J Clin Microbiol 18(3): 592595.

14. National Population Commission (NPC) National population census result (2006) Abuja Nigeria.

15. Joshua BO, Ronke CO (2015) Prevalence and antimicrobial susceptibility of MRSA and CoNS isolated from apparently healthy university students in Ota, Nigeria. Journal of natural sciences research 5(24).

16. APHA (1992) Compendium of Methods for Microbiological Examination of waste, ( $3^{\text {rd }}$ edn), American Public Health Association, Washington DC, USA.

17. Zaved HK, Rahman MM, Rahman A, Arafat SMY, Rahman MS, et al. (2008) Isolation and characterization of effective bacteria for solid waste degradation for organic manure. KMITL Sci Tech J 8(2): 44-55.

18. Cheesbrough M (2010) District laboratory practice in tropical countries. $\left(2^{\text {nd }}\right.$ edn), part two, University Press, Cambridge, UK. p. 47-54. 
19. Nwoire A, Madubuko EF, Eze UA, Oti-Wilberforce RO, Azi SO, et al. (2013) Incidence of Staphylococcus aureus in clinical specimens in Federal teaching hospital Abakalilki Ebonyi State 1(3): 043-046.
20. Baba T, Takeuchi F, Kuroda M, Yuzawa H, Aoki K, et al. (2002) Genome and virulence determinants of high virulence community-acquired MRSA. Lancet 359(9320): 1819-1827. 